\title{
Live-STREAMing in MeChANICAL ENGINEERING: AN INNOVATIVE APPROACH TO REMOTE LAB DELIVERY
}

\author{
Calynn Stumpf and Anita Parker \\ Faculty of Engineering, University of Alberta, Edmonton, Alberta \\ calynn@ualberta.ca, aparker@ualberta.ca
}

\begin{abstract}
In-person laboratories in undergraduate engineering provide students with tactile opportunities to build career-related skills, which are reflected in the graduate attributes of program accreditation criteria. Two Mechanical Engineering laboratory courses at the University of Alberta implemented live-streaming amidst the abrupt and indefinite move to online learning due to the COVID-19 pandemic over the Fall 2020 term. A highly motivated and technicallycompetent labinstructionalteam derived the necessary set-up of hardware, software, and personnel to implement pedagogical strategies that replicated the in-person experience with mechanical equipment as much as possible. This innovative approach enabled students to be involved in the demonstration of experiments in real time, interacting with teaching assistants and peers to ask questions and receive feedback. Students preferred live-streaming of labs as compared to pre-recorded videos.
\end{abstract}

Keywords: Engineering education, virtual or remote laboratories, live-streaming, online learning

\section{INTRODUCTION}

Hands-on experience in the laboratory (lab) setting is an essential component of the Mechanical Engineering program at the University of Alberta, primarily because of its impact on student learning and skill development. The Mechanical Engineering lab is a space where students can engage with industry-specific equipment and an experimental set-up from multiple angles, as well as ask questions and receive feedbackin real time. Lab instruction by teaching assistants (TAs) helps scaffold student mastery of several graduate attributes, as mandated by the Canadian Engineering Accreditation Board (CEAB), namely Problem analysis, Investigation, and Team work. [1]

Students enrolled in the Mechanical Engineering program are required to complete two lab courses in their third and fourth years of study-MECE 301 and MECE 403, respectively. In MECE 301, students operate tabletop mechanical equipment to conduct experiments. By comparison, MECE 403 brings in large-scale industrial equipment that is operated only by trained TAs; students actively observe and discuss the experiments in real time. An overview of the laboratory topics is provided in Appendix A.

As part of the response by the Department of Mechanical Engineering to the COVID-19 pandemic in mid-March 2020, continuation of in-person labs was not possible. The lab instructional team promptly created prerecorded videos to replace the in-person labs so that students could finish the Winter term. This initiative carried into the Spring and Summer terms, resulting in a collection of video resources for MECE 301 and MECE 403. Student feedback indicated that, while they appreciated these resources, the pre-recorded nature of the videos hindered the dynamic, unscripted experience provided by in-person learning. To address these concerns, and to better replicate the in-person experience while following pandemic restrictions, it was decided to employ live-streaming technologies and strategies for the wholly online, remote course delivery that was to come for the Fall 2020 term.

The purpose of this paper is to showcase the livestreaming of lab classes in MECE 301 and MECE 403 that occurred over the Fall 2020 term, including decisions made and lessons learned about the hardware, software, personnel, and pedagogical aspects such that this approach may be considered, utilized, or modified by similar programs at institutions elsewhere.

\subsection{Review of the Literature}

Laboratories in undergraduate engineering are essential for students to learn first-hand about the materials and forces of nature and to gain necessary skills for their future careers. $[2,3,4]$ The importance of the lab experience is reflected in the accreditation requirements of an engineering program. $[1,5]$ An increased prevalence of online learning in engineering education brings forth challenges of replicating the in-person lab in a nontraditional, geographically distanced setting.[6,7]

Non-traditional laboratory instruction can be achieved by a variety of means. First, virtual labs are imitations of real experiments, such as simulations that use software to model physical phenomena, or instructional videos that 
have been pre-recorded or are presented live with web conferencing. $[2,4,6]$ Live-streaming of laboratories fits in here; however, the literature is sparse with specific examples of this innovative approach being used in an engineering education context. Another non-traditional lab option is remote labs, which have an equipment set-up in a physical space that is accessed and manipulated by students at a distance through a computer interface.[2] Finally, lab kits are self-contained units of necessary materials that are provided to all students so that experiments can be conducted individually in their homes.[6]

Non-traditional laboratories remove the students' tactile interaction with instrumentation, as well as the opportunity for real-life miscalculations and mishaps, which are required for the development of important skills. $[5,8,9]$ Remote labs and lab kits can be expensive and complicated to create and maintain.[3] Lab kits also have safety concerns since students are unsupervised when working with materials, and there are logistical complications with their distribution.[6] A larger question overall is the ability of non-traditional labs to meet accreditation requirements in their standalone form. [6]

Drawbacks aside, non-traditional lab alternatives offer advantages that can foster deeper learning. Virtual labs can provide clean data, which supports understanding of concepts.[10] With simulations, students can perform unlimited repetitions, easily manipulate variables, and learn from failure without safety repercussions.[6] Simulations can be designed to bring otherwise unseen phenomena to life and remove confusing details while highlighting pertinent information. $[3,8,9,10]$ Prerecorded videos can be slowed down, paused, and replayed by the student as required. Live web conferencing with lab instructors offers increased social presence and the opportunity for students to ask questions in real time. Remote labs can optimize the use of space and are scalable as they provide access for many students to the same pieces of equipment.[3,9] Lab kits have been shown to increase student participation dramatically.[6]

Overall, all forms of non-traditional labs, when their financial and safety aspects are managed, can positively impact student learning. [2, 6,7,9] A clear distinction between student achievement in-person versus geographically distanced settings has not been made empirically.[2,11] Combining non-traditional lab innovations with in-person equivalents (e.g., having students watching a video demonstration prior to coming to a physical lab space) can maximize the advantages of each modality. Engineers, by nature, are problem-solvers and innovators who adapt to new technologies.[12] Student exposure to a variety of tools and data-collection techniques can well prepare them for this aspect of their future careers. [8]

\section{METHODOLOGY}

The live-streaming of MECE 301 and MECE 403 lab classes over the Fall 2020 term required specific hardware, software, and personnel to implement pedagogical strategies that replicated the in-person experience with mechanical equipment as much as possible in the online environment.

\subsection{Hardware and Software}

A visual representation of the hardware, software, as well as wireless and physical connections are provided in Appendix B. Two computers were used in the livestreaming. The main computer received physical and wireless connections from all the video and audio hardware and ran all the required software. A secondary computer was used only for the presenters to log into the virtual lab class from the student point of view, which provided a valuable perspective as a class unfolded.

Two cameras were used to capture video. The primary camera was a web camera fixed to a tripod with the intention that it remain stationary most of the time, although it could be moved when required. This camera was physically connected to the computer. The secondary camera was a smartphone camera attached to a gimbal so that it was portable, allowing the presenter to move freely around the room and show close-up and alternate views of mechanical equipment. The gimbal could be set down smoothly using a built-in tripod. The smartphone transmitted its video through a wireless Wi-Fi router, which was physically connected to the computer via an ethernet cable.

A wireless lavalier microphone system was used to capture audio. The unit worn by the presenter captured and transmitted the audio to a receiver, which was physically connected to the computer. Overall, the hard ware used was as follows:

- Main computing device with internet connection (e.g., laptop or desktop computer; Dell G7 7590);

- Secondary computing device with internet connection (optional, for presenter to see student view; Microsoft Surface Go);

- Primary video capture device (e.g., web camera);

- Tripod;

- Secondary video capture device (e.g., smartphone camera; Google Pixel 3a);

- Gimbal (DJI Osmo Mobile 3);

- Wireless Wi-Fi router

- Audio capture device (e.g., lavalier microphone system; Saramonic Blink 500).

The live-stream was broadcasted using Zoom video conferencing software. Zoom was chosen because it was already supported by the University of Alberta's learning management system. Students were only required to click 
on a Zoom link to join the class, and all the other software was behind the scenes. Open Broadcaster Software (OBS) was used to send a video feed to Zoom, as well as to easily switch between the two camera feeds. OBS received input from numerous video feeds and assigned them individually or grouped to "scenes". OBS would send a scene to Zoom as a single video stream using its virtual web camera feature. The primary video capture was sent directly into OBS; however, the secondary video capture (smartphone) required an application (IPWeb Camera) for its integration by OBS.

Audio captured by the microphone was modified through different software before being sent to Zoom. Zoom's built-in background noise suppression was sufficient for MECE 301; however, it was inadequate for the elevated equipment and environmental noise in the MECE 403 setting. In this case, an additional background noise suppression software was used (NVIDA RTX Voice). Finally, Equalizer APO was used to counteract a delay issue characteristic of Zoom. In summary, the software applications used were as follows:

- Zoom video conferencing platform;

- Open Broadcaster Software (OBS) live-streaming software;

- IP Web Camera to integrate smartphone video;

- NVIDIA RTX Voice for noise suppression;

- Equalizer APO to counteract delay issue.

Hardware and software choices and set-up were aligned with the following pandemic-related criteria:

- The instructor team (TAs) had adequate space to social distance themselves;

- The presenting TA could freely walk around the room and not be limited by wired devices;

- The presenting TA could provide close-up views of mechanical equipment with the portable smartphone camera;

- Students attending the lab virtually could interact with the TA performing the experiment in real time with the Zoom chat function.

\subsection{Personnel/Pedagogical}

The live-streaming instructor team during the lab consisted of a minimum of two TAs, each with a specific role. One TA was the "presenter" who verbally and visually conducted an experiment for a student audience in real-time. The presenter spoke to the students through the main web camera and used the smartphone camera on a gimbal to provide auxiliary views of mechanical equipment and readings for data collection. Another TA was the "hardware/software operator and director" who ran the live-streaming set-up. The director would switch between different video scenes or presentation slides and was also responsible for engaging with students in the Zoom chat. In some lab classes, students were sent into breakout rooms to discuss specific questions. When possible, a third TA helped with large scale equipment and camera operation.

\section{FINDINGS}

Because MECE 301 and MECE 403 lab classes throughout the Fall 2020 term were being planned, prepared, and delivered in quick succession, the lab instructional team encountered numerous challenges that required immediate attention. Most of issues were related to hardware or software, with a few relating to personnel/pedagogical aspects. Table 1 categorizes a few of the more notable problems and solutions, which have now transformed into lessons learned to guide future livestreaming efforts.

Table 1: Some problems encountered during the Fall 2020 term.

\begin{tabular}{|c|c|}
\hline Problem & Solution \\
\hline \multicolumn{2}{|c|}{ Hardware } \\
\hline $\begin{array}{l}\text { Interference between } \\
\text { smartphone and microphone } \\
\text { transmitter on Wi-Fi }\end{array}$ & $\begin{array}{l}\text { Move the smartphone onto } \\
\text { the } 5 \mathrm{GHz} \text { band on the Wi-Fi } \\
\text { router since the microphone } \\
\text { operates on the } 2.4 \mathrm{GHz} \text { band }\end{array}$ \\
\hline $\begin{array}{l}\text { Computer not powerful } \\
\text { enough to run all software } \\
\text { and therefore drops video } \\
\text { quality to reduce CPU load }\end{array}$ & $\begin{array}{l}\text { Use a more powerful } \\
\text { computer }\end{array}$ \\
\hline $\begin{array}{l}\text { Equipment with light that } \\
\text { flashes will produce image } \\
\text { aliasing due to equipment } \\
\text { operating frequency and } \\
\text { camera frame rate }\end{array}$ & $\begin{array}{l}\text { Provide students with an } \\
\text { image of equipment results } \\
\text { alongside the live-stream } \\
\text { video }\end{array}$ \\
\hline \multicolumn{2}{|c|}{ Software } \\
\hline $\begin{array}{l}\text { Low video quality in Zoom } \\
\text { when sharing video feed } \\
\text { through traditional method } \\
\text { ( } 640 \times 360 \text { pixels) }\end{array}$ & $\begin{array}{l}\text { Maximize video quality by } \\
\text { using the Zoom's "share } \\
\text { screen" option with "content } \\
\text { from a 2nd camera" sub- } \\
\text { option (1280 x } 720 \text { pixels) }\end{array}$ \\
\hline $\begin{array}{l}\text { Audio/video synchronization } \\
\text { issues when sharing content } \\
\text { from a } 2 \text { nd camera }\end{array}$ & $\begin{array}{l}\text { Use Equalizer APO and add } \\
\text { a } 1.3 \text { second delay to the } \\
\text { audio }\end{array}$ \\
\hline $\begin{array}{l}\text { Smartphone video camera } \\
\text { feed cannot be zoomed in }\end{array}$ & $\begin{array}{l}\text { Create a scene in OBS with } \\
\text { the video feed and scale the } \\
\text { video feed up by } 100 \% \text { to } \\
\text { replicate a zoom factor of } 2 X\end{array}$ \\
\hline \multicolumn{2}{|c|}{ Personnel / Pedagogical } \\
\hline $\begin{array}{l}\text { Presenter's moral low when } \\
\text { presenting to a black screen }\end{array}$ & $\begin{array}{l}\text { Added additional monitor to } \\
\text { laptop for presenter to see } \\
\text { students web cameras }\end{array}$ \\
\hline $\begin{array}{l}\text { Live streaming quality is } \\
\text { dependent on internet } \\
\text { connection of TAs and } \\
\text { Student and could vary }\end{array}$ & $\begin{array}{l}\text { Along with the live stream, } \\
\text { also allow students to access } \\
\text { pre-recorded videos created } \\
\text { in Spring/Summer term }\end{array}$ \\
\hline
\end{tabular}


The transition to live-streaming for MECE 403 labs was not overly difficult, since traditionally TAs run the lab while the students observe and record data. For MECE301, however, the live-streaming delivery was more of a departure from its pre-pandemic version wherein students complete the lab on their own and TAs assist as required. The live-streaming of MECE 301 labs also had to take into consideration the tabletop nature of the experiments. Here is how a typical live-streamed MECE 301 lab unfolded:

- TAs arrive thirty minutes before the scheduled start time to ensure all the lab and live-streaming equipment is working properly.

- In Zoom, a "lab start" message screen is displayed through OBS with a countdown on when the lab will start. This allows students to join the meeting and know when they should be ready.

- After the countdown ends, the view is switched to the web camera. The presenter TA introduces the team and overviews the upcoming lab.

- When showing specific equipment that will be used in the lab, the view is switched between the web camera (used for providing a view of the entire setup and presenter), and the smartphone camera (used to display a close-up view of the equipment)

- When transitioning to a new experimental setup, a "repositioning the camera" message screen is displayed with a countdown timer. This reduces instances of motion sickness for viewers as the cameras are shuffled around and indicates the length of the break.

- If a computer program is required to be displayed to the students, the screen is shared from that device. If this is not possible, one of the cameras is used to record the screen.

- Instead of having students record data during the livestream, they are instead provided with pre-recorded data. This eliminates issues of equipment malfunctioning while also providing consistency across all labs group throughout the week.

- After the lab demo is completed, the TA will review the lab and go through the required assignment (worksheet or lab report) and address FAQ with the students.

- After the formal end of the lab, the TA stays in the Zoom meeting for thirty additional minutes to answer any additional questions from students.

MECE 301 students were informally and anonymously surveyed about which lab class delivery mode they preferred-pre-recorded videos, live-streaming, or a combination. Most students ( $75 \%$ of respondents, $\mathrm{N}=38$ ), as shown in Figure 1, indicated a preference for a combination, and some commented that they enjoyed the real-time aspect of the live-streaming but also appreciated the availability and quality of the pre-recorded videos. Beyond this, no data has yet been obtained about the experience or impact of the live-streaming initiative, although this can be considered once the pandemic-driven teaching and learning situation normalizes.

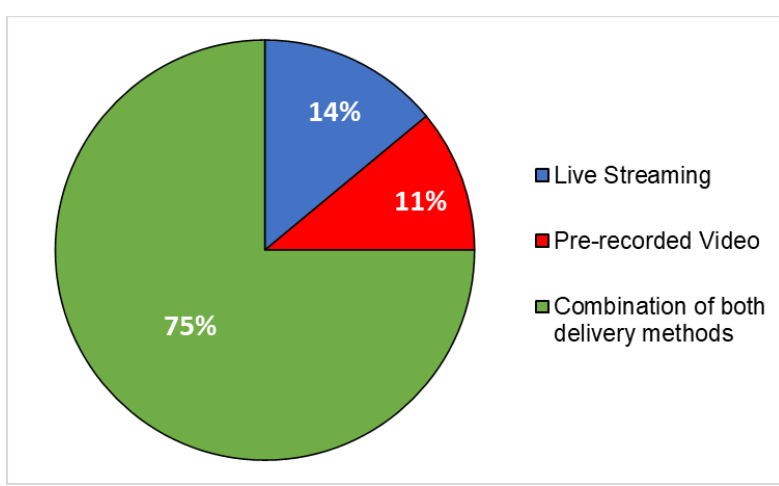

Fig. 1. Informal survey results $(\mathrm{N}=38)$ of students' preferred lab delivery mode

\section{DISCUSSION}

Skill building in the operation of mechanical equipment and collection of experimental data requires physical, inperson participation by students. In a situation such as COVID-19 where this is not possible, there are a number of alternatives to consider rather than omitting this important aspect of undergraduate engineering education. Live-streaming is one means of non-traditional lab instruction wherein experiments are conducted in real-time by TAs and broadcasted to students through video conferencing. Students attend the lab virtually at a set day and time and benefit from an orchestration of behind-thescenes technical and pedagogical efforts by a team of TAs. This was the method chosen by the Department of Mechanical Engineering at the University of Alberta for the Fall 2020 term, specifically for the online, remote versions of MECE 301 and MECE 403.

For the lab instructional team, implementing livestreaming throughout the term was an exercise in experiential learning about the complexity of teaching. As is characteristic of the engineering discipline itself, illdefined and multifactorial problems were encountered, brainstormed, and solved collaboratively. From the perspective of the lab instructional team, as well as from informal student accounts, the greatest benefit of livestreaming was the opportunity for students to ask questions and receive feedback in real-time. The TA presenting an experiment could make in-the-moment adjustments, such as providing clarification, repeating a procedural step, addressing a misunderstanding, and more.

Seemingly the most obvious limitation of livestreaming would be its complex technical set-up and long list of potential mishaps in the moment. While many problems of this nature were resolved, a notable pedagogical downside reported by the TA presenters was lower engagement by students as due to their absence from 
the physical lab space. TAs were encouraged to conduct an offline, dry-run of their experiments prior to a livestreaming session so that they could better focus on the teaching aspects of the lab, such as engagement, when meeting students on Zoom.

In the virtual lab space provided by live-streaming, students did not have the opportunity to physically manipulate equipment and variables; however, the advanced hardware and software configuration and the coordinated delivery by TAs helped maintain social presence, accountability, and the collaborative creation of knowledge, which are normally restricted to in-person experiences. The live-streaming initiative in the Department of Mechanical Engineering over the Fall 2020 term was driven by the importance of maintaining the lab component of the program as much as possible given the circumstances. Methods employed, problems encountered, and lessons learned are continuing to inform the Winter 2021 offering of the MECE lab courses, which are in progress at the time of writing this paper.

\section{CONCLUSION}

Hands-on experience for students in an undergraduate engineering program that scaffolds their mastery of skillbased CEAB graduate attributes and prepares them for future careers is non-negotiable. When students enrolled in the Mechanical Engineering program at the University of Alberta abruptly switched to online learning in mid-March 2020 , the lab instructional team created a library of prerecorded videos of lab demonstrations to finish the Winter term and for use in the Spring and Summer terms.

However, a better pedagogical solution was required, and it was decided to implement live-streaming for lab delivery over the Fall 2020 term. The high motivation and technical competence of the lab instructional team resulted in the hardware, software, personnel, and pedagogical aspects of the endeavour being worked out. Issues were resolved collaboratively and quickly, and students achieved the course learning outcomes despite pandemic restrictions. It was found that the pre-recorded videos were a valuable supplemental resource for the live-streaming sessions. Moving forward, still at a time of uncertain teaching circumstances in 2021, successful live-streaming of labs in MECE 301 and MECE 403 continues as a direct result of the expertise and insight of the instruc tional team.

\section{Acknowledgements}

The authors wish to acknowledge the Department of Mechanical Engineering and the Faculty of Engineering at the University of Alberta for supporting the live-streaming of laboratories initiative.

\section{References}

[1] Engineers Canada, Canadian Engineering Accreditation Board 2019 Accreditation Criteria and Procedures, Engineers Canada, 2019.

[2] J. R. Brinson, "Learning outcome achievement in non-traditional (virtual and remote) versus traditional (hands-on) laboratories: A review of the empirical research.," Computers \& Education, vol. 87, pp. 218-237, 2015.

[3] L. D. Feisel and A. J. Rosa, "The role of the laboratory in undergraduate engineering education," Journal of Engineering Education, vol. 94, no. 1, pp. 121-130, 2005.

[4] F. Moosvi, S. A. Reinsberg and G. W. Reiger, "Can a hands-on physics project lab be delivered effectively as a distance lab?," International Review of Research in Open and Distributed Learning, vol. 20, no. 1, pp. 21-42, 2019.

[5] J. Glassey and F. D. Magalhaes, "Virtual labs - love them or hate them, they are likely to be used more in the future," Education for Chemical Engineers, vol. 33, pp. 76-77, 2020.

[6] S. Badjou and R. Dahmani, "Current status of online science and engineering education," Journal of Online Engineering Education, vol. 4, no. 1, p. 9pp., 2013.

[7] S. Ray and S. Srivastava, "Virtualization of science education: A lesson from the COVID-19 pandemic," Journal of Proteins and Proteomics, 31 May 2020.

[8] T. de Jong, M. C. Linn and Z. C. Zacharia, "Physical and virtual laboratories in science and engineering education," Science, vol.340, no.6030, pp.305-308, 19 April 2013.

[9] V. Potkonjak, M. Gardner, V. Callaghan, P. Mattila, C. Guetl, V. M. Petrovic and K. Jovanovic, "Virtual laboratories for education in science, technology, and engineering: A review," Computers \& Education, vol. 95, pp. 309-327, 2016.

[10] M. Seifan, N. Robertson and A. Berenjian, "Use of virtual learning to increase key laboratory skills and essential non-cognitive characteristics," Education for Chemical Engineers, vol. 33, pp. 66-75, 2020.

[11] L. S. Post, P. Guo, N. Saab and W. Admiraal, "Effects of remote labs on cognitive, behavioral, and affective learning outcomes in higher education," Computers \& Education, vol. 140, p.9pp., 2019.

[12] M. D. Koretsky and A. J. Magana, "Using technology to enhance learning and engagement in engineering," Advances in Engineering Education, vol. 7, no. 2, p. 53pp., 2019. 
APPENDIX A: LABORATORY TOPICS FOR MECE 301 AND MECE 403

\begin{tabular}{|l|l|}
\hline \multicolumn{1}{|c|}{ MECE 301 Lab Title } & \multicolumn{1}{c|}{ Description } \\
\hline Dimensional Measurement & $\begin{array}{l}\text { Calipers (Vernier and Digital) and Micrometers are used to measure gauge blocks and a } \\
\text { machined part }\end{array}$ \\
\hline Digital Measurement & $\begin{array}{l}\text { A Linear Variable Differential Transformer (LVDT) connected to an oscillating platform } \\
\text { is measured using an Analog to Digital Convertor (ADC) }\end{array}$ \\
\hline Displacement Transducers & $\begin{array}{l}\text { An LVDT, Conductive Film Potentiometer, and Two Coil Inductive Transducer is used to } \\
\text { measure displacement }\end{array}$ \\
\hline Strain Measurement & $\begin{array}{l}\text { Strain gauges connected to a Wheatstone bridge are used to measure strain in a tensile test } \\
\text { machine }\end{array}$ \\
\hline Rotation Measurement & $\begin{array}{l}\text { Direct contact Tachometer, Photoelectric Tachometer, and Stroboscope are used to } \\
\text { measured rotational speed }\end{array}$ \\
\hline Pressure Measurement & A Barometer and a Dead Weight Tester are used to measure pressure \\
\hline Flow Measurement & $\begin{array}{l}\text { Air velocity and flow rate are measured using Pitot Tubes, Hot Wire Anemometer, and } \\
\text { various restriction flow meters }\end{array}$ \\
\hline Temperature Measurement & $\begin{array}{l}\text { The temperature of water and a surface are measured through direct contact (Glass } \\
\text { Thermometer, Thermocouples, and thermistor) and with an Infrared Thermometer }\end{array}$ \\
\hline
\end{tabular}

\begin{tabular}{|l|l|}
\hline \multicolumn{1}{|c|}{ MECE 403 Lab Title } & \multicolumn{1}{c|}{ Description } \\
\hline Pumps & Pumps in series and parallel configurations in a flow loop measuring pump performance \\
\hline Bolted Joints & $\begin{array}{l}\text { Bolted joints in a tensile testing machine measuring the effects of bolt preload, gaskets, } \\
\text { and alternating stress }\end{array}$ \\
\hline Vibrations & Forced and free vibrations in a single degrees of freedom system \\
\hline Stress Concentrations & Strain concentration caused by a hole in a plate \\
\hline Refrigeration & Vapour compression refrigeration system \\
\hline
\end{tabular}


APPENDIX B: HARDWARE AND SOFTWARE SET-UP IN THE LIVE-STREAMING OF LABS
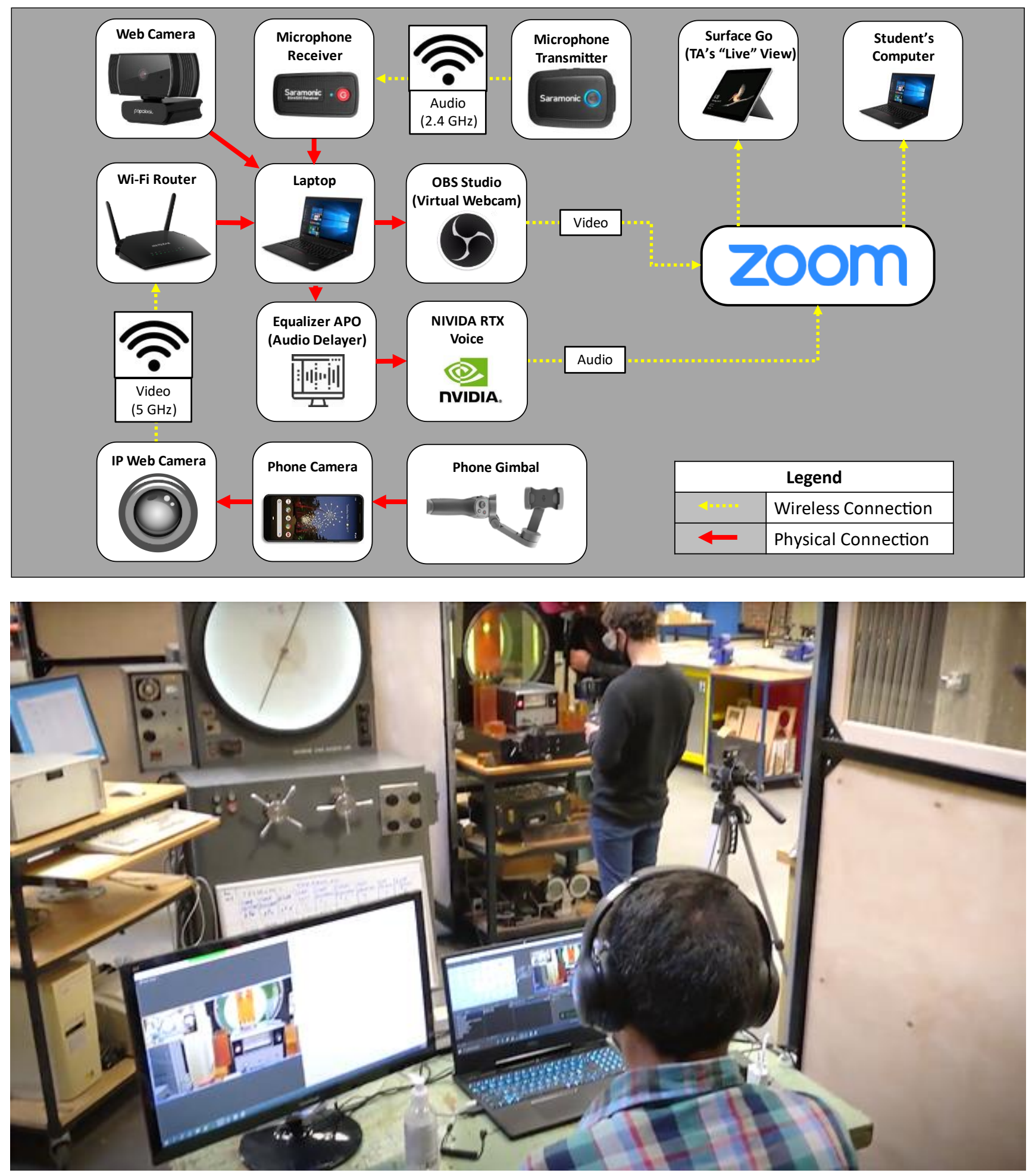